Article

\title{
How Reputation Systems Change the Psychological Antecedents of Fairness in Virtual Environments
}

\author{
Stefania Collodi ${ }^{1, *}$, Maria Fiorenza ${ }^{1}$, Andrea Guazzini ${ }^{1,2}$ and Mirko Duradoni ${ }^{3}$ \\ 1 Department of Education, Languages, Intercultures, Literatures and Psychology, University of Florence, \\ 50135 Florence, Italy; maria.fiorenza@stud.unifi.it (M.F.); andrea.guazzini@unifi.it (A.G.) \\ 2 Center for the Study of Complex Dynamics (CSDC), University of Florence, 50135 Firenze, Italy \\ 3 Department of Industrial Engineering, University of Florence, 50139 Florence, Italy; mirko.duradoni@unifi.it \\ * Correspondence: collodistefania@gmail.com
}

Received: 15 May 2020; Accepted: 7 August 2020; Published: 9 August 2020

\begin{abstract}
Reputational systems promote pro-social behaviors, also in virtual environments, therefore their study contributes to the knowledge of social interactions. Literature findings emphasize the power of reputation in fostering fairness in many circumstances, even when its influence is not directly oriented towards specific individuals. The present study contributes to the investigation of the psychological antecedents of fairness, introducing (or not) reputation in the social dilemma framework. Although reputational systems usually influence fairness dynamics, there are also socio-psychological characteristics that can play a role, affecting the adhesion to the norm online. To investigate their effects, we employed a virtual bargaining game that could include a reputational system depending on the experimental condition. Results show that the participant's fairness could be significantly influenced by socio-psychological and demographic characteristics, as well as personality traits. Reputation seems to decrease fairness in those individuals who report high levels of Neuroticism and Openness. At the same time, high values of Self-Efficacy appear to be more likely associated with unfair behaviors when reputation is off the bargaining. Finally, Age and Sense of Community emerge as fairness promoters regardless of the experimental condition.
\end{abstract}

Keywords: fairness; personality; reputation; online bargaining game; behavior's psychological antecedents

\section{Introduction}

In the literature, personality traits are defined as the "dimensions of individual differences in tendencies to show consistent patterns of thoughts, feelings, and actions" [1]. Personality affects individual actions, along with well-established behaviors [2,3]. Also within the virtual environment personality represents one of the strongest predictors of people's conducts in several contexts [4]. Intending to discover which psychological variables come into play when people face social dilemmas, recent research focuses on the personality traits that affect players' behaviors and social influence susceptibility when reputation information (i.e., a summary of what other players think about a target's previous behaviors) is included in an online game [5].

Along the same line of research, this study aims at discovering the psychological antecedents of fairness in the bargaining game context and deepening the knowledge of the social influence exerted by reputational systems (i.e., those systems that collect, distribute, and aggregate feedback about participants' past behavior) [6]. Innovatively, this research not only focuses on the effects reputation has on third parties (i.e., rather than on the one who takes action), but it also identifies which socio-demographic and psychological variables impact on fair plays. The results show that different psychological characteristics modulate the bargaining behavior and, the inclusion of a reputational system in the virtual game, increases the number of socio-psychological variables that influence players' fairness. 


\subsection{Personal and Contextual Influences on Fairness and Adhesion to the Norm}

In the last 50 years, the idea of "homo economicus" has been questioned by the scientific community, and the view of human beings as only dominated by personal interests is now considered outdated [7,8]. Recent research expanded the knowledge of human sociality through simple and anonymous laboratory games [9], which provided evidence about fair behaviors, revealing that people usually do not pursue selfish interests (i.e., profits), but follow the norm of reciprocity, favoring fair interactions among individuals [10].

Social norms, like reciprocity and fairness, spread among human society thanks to the efforts of those who enforce such norms, support them even if it costs some fitness, for example, rewarding cooperative individuals and punishing uncooperative partners (i.e., altruistic punishment) $[7,10]$.

The concept of "competitive altruism" was developed to explain all the expensive behaviors that individuals perform for others' benefit [11]. Despite the initial cost that such behaviors imply, they appear to be convenient in the long-term, making cooperators more attractive partners for future interactions than uncooperative interactors [12]. A large number of economic studies (e.g., bargaining games, [13]) documented how pro-social norms play a central role in orienting players' behaviors, although altruistic acts can be risky and pricey [14]. A study by Gunnthorsdottir, McCabe, and Smith [15], showed how both in an anonymous dictator and bargaining game, the participants tended to collaborate with the others, engaging in cooperative exchanges and fair divisions, rather than exploiting the context to get the full advantage.

Context manipulation can influence the impact that social norms have on people's behavior. For instance, Collodi et al. [5] included a reputational system in a modified Ultimatum Game and investigated the effects that the social influence exerted by reputation, combined with specific personality traits and psychological characteristics, had on the players' conducts.

Social dilemmas have been employed to investigate the effects of reputation on the achievement of collective goals. Semmann and Krambeck [16] found that the participants' need to preserve a good reputation brought them to cooperate in a public good game, showing high levels of pro-social behavior. At the same time, when reputation was off the table, the players' contribution to the public good dropped to zero. Other studies corroborated such evidence, showing that individuals tended to be more cooperative when there was a chance to improve their reputation [16-20]. In a more recent study, the mere inclusion of a reputational system in a social dilemma context determined an increase of fair behaviors in those players who were not personally affected by reputation gain or loss [21].

Reputation mechanisms and their associated influence, change people's behavior, and affect the subjective perception of fairness [22,23].

Social influence susceptibility, as well as norms compliance, appears to be mediated by situational (e.g., where the interaction occurs) and personal factors (e.g., psychological characteristics) [24].

As to the environmental part, the Social Identity Model of Deindividuation Effects (SIDE), demonstrated how certain peculiarities of the online scenario (i.e., anonymity, physical isolation, scarce identifiability, and social identity salience) determine higher levels of conformity to the local norms [25,26]. Usually, reputation is built on social norms [27] and represents a social cue on which people rely to adapt their behavior (e.g., avoid cheaters) [28], thus representing a source of social influence. Combining the properties of the online environment with the influence exerted by reputation in an online social dilemma, it is more likely to observe higher levels of conformism to the norms of this specific context, and consequently to observe more pro-social behaviors [21].

Regarding the personal factors, personality traits [29], age, and gender [30] can influence the adherence to the norms conveyed by the context, such as fairness [3,24]. Several studies put the Big Five Personality Factor model [1,31-33] and its dimensions (i.e., neuroticism, openness to experience, extraversion, agreeableness, and conscientiousness) in relation to norms, such as cooperation.

Susceptibility to social norms appeared to be associated with conscientiousness [34,35] and agreeableness [32,33,36-38], but not with extraversion, neuroticism, and openness [34]. Proto and Rustichini [35], employing a modified version of the Trust Game, found that participants 
with the highest conscientiousness values were more effective during cooperation tasks compared to unconscientious individuals. Conscientious players appeared to be also more susceptible to norms, such as cooperation, compared to unconscientious ones [34].

Also, agreeableness emerged as a personality trait capable of promoting pro-sociality. Koole et al. [32] employed a Resource dilemma to put in relation personality traits, cooperation, and interaction setting. Agreeableness appeared to be capable of predicting cooperation, even if situational variables mediated such a relation [32]. Using a Public Good game, Volk, Thöni, and Ruigrok [33] investigated the relationship between agreeableness and cooperation. Their results showed that that individuals with low levels of agreeableness presented more stable selfish preferences during the game, compared with agreeable players. Volk, Thöni, and Ruigrok [33] suggested agreeableness as a strong predictor of pro-sociality.

According to the literature, cooperation seems not to be influenced by neuroticism and openness [32,34], while results on extraversion are not precise. In fact, even if extroverted individuals appeared to be less susceptible to norms [34], they also behaved pro-socially in a Resource dilemma [32].

Mixed results emerged on the effects of gender on fair behaviors [39,40], while there is evidence in the literature suggesting that they increase with maturity [21]. Investigated through the Prisoner dilemma, it is not clear if cooperation prevails among women [41,42], men [43-45], or if there is no difference between them [46-48].

Furthermore, another individual characteristic that affects potential cooperative behaviors is Self-Efficacy. According to the literature, Self-Efficacy promotes competitive behaviors and good performance [49]. Simultaneously, when people can judge others or are exposed to their evaluations, competitive and selfish behaviors become less frequent. As shown by numerous experimental studies, reputational systems favor collaborative choices and fair behaviors, making Self-Efficacy less capable of predicting competition [50,51].

With respect to the social dimension of interaction, susceptibility to norms and adhesion are tied to the group context. One factor that literature considered along with pro-social and cooperative behaviors is the Sense of Community [52]. Scientific evidence suggests that a large group's identification is associated with positive evaluations of the other members and increased levels of trustworthiness and cooperativeness that favor the onset of cooperative dynamics [53].

\subsection{Aims of the Study and Hypothesis}

Inspired by the work of Duradoni et al. [21], where the effects of reputation on fair allocations and trust dynamics in an online bargaining game were tested, we employed the same experimental paradigm to investigate which socio-psychological characteristics can be identified as the antecedents of fairness. The bargaining game has been developed to study and quantify pro-social gossip dynamics. In this scenario, a third-party observer may or may not share negative evaluations about a target exploitative/negative behavior to stop it and thus increase overall cooperation [54]. Pro-social-gossip dynamics are, for instance, an essential part of forum content moderation $[55,56]$ and third-party product review [57]. In the latter case, reputation is already used to deal with spam reviews and the subsequent gradual credibility loss of the system [58]. The environment characteristics where pro-social gossip occurs appeared to affect people's fairness in a non-trivial way. Indeed, the previous work of Duradoni and colleagues [21] showed that reputation did not affect Observer's behavior (and consequently pro-social gossip levels) but rather the one of those actors who were not targeted by the reputation (i.e., proposers). Thus, fairness increased while pro-social gossip remained stable. According to their results, in social dilemma games, Proposers, respectively, those who propose a deal to the Receivers, adjust their allocation behavior basing themselves on the mere existence of a reputational system, even if it does not concern them (i.e., it was dedicated to other game's roles). In other words, players appeared to allocate more resources when reputation was involved in the game, although they did not have any reputation to manage or reputational benefits from acting pro-socially. Therefore, the present work aims at extending previous pieces of evidence about the social 
influence exerted by reputation, using the social dilemmas framework. In particular, it investigates which socio-demographic and psychological characteristics produce an increase in fair behaviors among Proposers. Furthermore, it also explores which personality traits are associated with fairness by referring to the Big Five, distinguishing between two different game's contexts: with or without the reputational system. In the light of the literature results, we propose the following hypothesis, summarized in Table 1.

Table 1. Summary of the experimental hypothesis. The table reports the literature predictions on the socio-demographic and psychological antecedents of fairness when a reputational system is (or is not) involved in the game context.

\begin{tabular}{lcc}
\hline \multicolumn{2}{c}{ Experimental Hypothesis } \\
\hline Variable & Reputation OFF & Reputation ON \\
\hline \multirow{4}{*}{ Fairness } & Extraversion (-) \\
& Age $(+)$ & Neuroticism (-) \\
& Sense of Community $(+)$ & Openness (-) \\
& & Consceableness (+) \\
& & Age (+) \\
& & Self-Efficacy (0) \\
& & Sense of Community $(+)$ \\
\hline
\end{tabular}

Note: $+=$ Positive relationship expected; $-=$ Negative relationship expected; $0=$ No relationship expected.

Hypothesis 1 (H1). Following the results of Koole et al. [32] on the relation between personality and cooperation in the Resource dilemma scenario and the evidence reported by De Young et al. [34], we hypothesize that when the bargaining game involves reputation, individuals who report high levels of neuroticism and openness will not behave fairly given their scarce susceptibility to social norms (i.e., reputation makes the norm of the bargain game salient). Coherently with Koole et al. [32], De Young et al. [34], and Volk, Thöni, and Ruigrok [33] it can be assumed that players characterized by high scores of agreeableness will likely report the highest levels of Fairness, along with conscientious individuals [34,35]. Finally, given the peculiar context of the bargaining game and the scarce susceptibility of extroverted individuals to social norms, we suggest that participants defined by this personality trait will not play fair [34].

Hypothesis 2 (H2). In accordance with previous research findings on age in the bargaining context [21], we hypothesize that with as the participants' age grows, fair behaviors will be more frequently performed. We expect Fairness to be fostered by age and maturity, along with previous scientific pieces of evidence [21].

Hypothesis 3 (H3). Self-Efficacy prevents fair behaviors in competitive settings. A reduction of fairness is expected in the bargaining game context with no reputational system given the association between Self-Efficacy and competitiveness [49]. It is also possible to assume that the social influence exerted by reputation, when it is included in the game, will affect the interaction context, reducing the competitive element, and eliminating the effects of Self-Efficacy [21].

Hypothesis 4 (H4). According to the literature on Public Good dilemmas, the group's identification is associated with high levels of trustworthiness and cooperativeness among its members [52]. We assume that a strong Sense of Community will favor the onset of Fairness in the bargaining game context, given its association with cooperativeness and pro-sociality found by previous research [52].

\section{Material and Methods}

\subsection{Participants and Design}

The study sample was composed of 216 participants (112 male and 104 females), recruited through a voluntary census, with an average age of 17.72 (standard deviation 3.63) and with an 
average household size of 4.02 (standard deviation 1.14). Experimenters recruited the participants at high schools and universities doors in the metropolitan area of Florence, registering volunteers' phone numbers or email addresses to contact them later. $31.9 \%$ of the sample was made by University students, while $68.1 \%$ was composed of high-school students. Following the Italian Psychological Association guidelines, every participant received the informed consent and could leave the session at any moment. An Internal Institutional Review Board supervised the research activity to ensure anonymity and the respect of the World Medical Association (WMA) Declaration of Helsinki principles applied to social sciences. All the participants completed the experiment. The study design involved two experimental conditions: "Reputation OFF" and "Reputation ON." In the first case, no reputational information was provided to the players, while in the second one, such information was included in the game. Participants played the game in a group of six people, who could be both males and females, for a total of 36 groups. Gender was balanced between conditions. Table 2 shows the study design, the number of participants, and their gender.

Table 2. Experimental design and number of participants for each condition with gender specification.

\begin{tabular}{lccc}
\hline \multicolumn{4}{c}{ Experimental Design and Participants } \\
\hline & Males & Females & Total \\
\hline Reputation OFF & $58 \%(54 \%)$ & $50 \%(46 \%)$ & $108 \%(50 \%)$ \\
\hline Reputation ON & $54 \%(50 \%)$ & $54 \%(50 \%)$ & $108 \%(50 \%)$ \\
\hline Total & $112 \%(52 \%)$ & $104 \%(48 \%)$ & $216 \%(100 \%)$ \\
\hline
\end{tabular}

\subsection{The Software}

The bargaining game source code was provided by the Virtual Human Dynamics Laboratory (VirtHuLab), which developed the software [21]. The game involves six anonymous players gathered in a group, and each participant covers the role of Proposer, Observer, and Receiver for 15 rounds in a specific sequence set by the system. The first role covered by the player is therefore random, and the participant becomes aware of it as soon as he logs in. Turn shifting is organized to make the participant play a specific role just one time before moving to another; in other words, the participant who starts as Proposer will cover the same position one time out of three with a different interactor. Therefore, each player interacts three times with every single member of the group in each role. The total number of rounds is 45, and the game lasts approximately 30 minutes. Early in the game, each player is equipped with three different types of virtual resources, namely Gold, Power, and Happiness, that are functionally the same. One of these resources is attributed a value of 50 units (i.e., maximum resource), while to the others is attributed a value of five units (i.e., minimum resource). Following this rule, resources are randomly distributed to the participants at the beginning of the session. The player who completes the game with the highest amount of the minimum resource is the winner. The following example was provided to the participants "if Player A has at the end of the 45 rounds 25 Gold, 13 Power, and 17 Happiness and Player B has 10 Gold, 30 Power, and 25 Happiness, Player A score will be represented by his amount of Power while for Player B the score will be calculated upon his quantity of Gold." Each player can check both his real-time score and the other players' one, on the right side of the screen, as well as control the other players' scores. Each participant can recognize his points thanks to a nickname, while the other players remain unknown to him/her except for their role (i.e., Proposer, Observer, and Receiver), apart from the Observer that can be characterized by reputation when the experimental condition so provides. The nicknames of the other players can only be seen in the final chart. In this way, players' decision making is not influenced by turn memory, and interactions stay anonymous. In each role, players must complete different tasks and reach various goals. For instance, the Proposer must bargain with the Receiver offering part of the maximum resource in return for part of the minimum one. The difference between the maximum resource offer and the minimum resource request made by the Proposer has been used to estimate his Fairness. Fairness is, therefore, the difference between the offer 
and the request of the Proposer. The Receiver has only partial information on the deal; he can only see the quantity and the type of resource offered by the Proposer, without knowing what and how much will be asked in return. The Receiver can either accept or refuse straight away the allocation or he can ask the Observer, who is completely aware of the bargaining details, for suggestions. The Observer can judge the Proposer's behavior depending on the quantity and type of resources type of resources he offered and requested. At the same time, the Observer can suggest to the Receiver to accept or refuse the deal, as well as decide to give no suggestions. After the Receiver decides to accept (or refuse) the offer, Proposer's request is revealed, and the resources transaction occurs (or not). When the experimental condition so provides (i.e., Reputation ON condition) and the reputational system is provided, a reputation score characterizes the Observer. Such a score is built on the Receivers' feedback on the Observer's suggestions referring to previous interactions. Observers are not aware of their evaluation and reputation.

\subsection{Psychological Measures}

To identify the antecedents of fair behaviors in an online bargaining game, we administered a computer survey investigating the sample Socio-demographic characteristics, Personality traits, Self-Efficacy, and Sense of Community. The survey was divided into four sections, organized as follows:

- Socio-demographic form. It is composed of five questions about gender, age, education, household size, and parents' marital status.

- $\quad$ Five-Factor Adjective Short Test (5-FasT) [59]. It is a short version of the Five-Factor Model and investigates the traits of Neuroticism, Extraversion, Agreeableness, Closeness, and Consciousness using 26 adjectives. For each adjective, participants indicate how much they describe their personality on a five-point Likert scale (from $1=$ "not at all", to $5=$ "very much"). All the subscales are characterized by good reliability (Neuroticism $\alpha=0.78$; Extraversion $\alpha=0.73$; Agreeableness $\alpha=0.71$; Closeness $\alpha=0.71$; Consciousness $\alpha=0.70$ ).

- General Self-Efficacy scale [60]. General self-efficacy is the belief in one's competence to cope with a broad range of situations and demands and reflects a generalization across various domains of functioning in which people judge how efficacious they are [61]. This scale investigates the Self-Efficacy perception of the participants and is made of ten items on which participants have to express their level of agreement on a four-point Likert scale (from 1 = "not true at all", to $4=$ "totally true"). According to the review by Luszczynska and colleagues [62], the internal consistency coefficients of the measure ranges from 0.75 to 0.91 .

- Classroom Community scale [63]. This 20-item scale investigates the participants' classroom Sense of Community. Two subscales, ten items each, comprise the instrument and consider the classroom both as a social and a learning community. With respect to the first subscale, classroom as a social community, some items examples are: "I feel that students in this course care about each other"; "I feel connected to others in this course"; "I do not feel a spirit of community." As regards the second subscale, classroom as a learning community, some items examples are: "I feel that I am encouraged to ask questions"; "I feel that it is hard to get help when I have a question"; "I feel that I receive timely feedback." For each assertion, participants should express their level of agreement relying on a five-point Likert scale (from 1 = "strongly disagree", to $5=$ "strongly agree"). The overall scale reliability is $\alpha=0.93$, while for the social community is $\alpha=0.92$, and for the learning community $\alpha=0.87$ [64].

\subsection{Procedures}

For the experiment, the School of Psychology computer laboratory at the University of Florence was employed. Participants were accompanied one by one in the room until the group of six was gathered. Researchers provided the participants with all the necessary information for the experimental session and their id number to guarantee their anonymity. Data anonymity was therefore secured 
by randomly assigning the id number to the players; thus, it was not possible to attribute specific actions to specific natural persons. A PowerPoint presentation was used to explain the survey and the rules of the bargaining game. The researchers answered all the questions. After the introduction, each participant reached his computer station, which was separated from the others by barriers to ensure physical isolation. Participants were not allowed to talk to each other, except for technical issues; therefore, all the interactions happened anonymously and via computer. At the end of the experimental session, all the players received a brief debriefing. Only one experimental session was planned for each six-participants group. Depending on their experimental condition, the participant could play with or without the reputational system, but not with both at the same time. No compensation was given.

\subsection{Data Analysis}

First, we verified the homoscedasticity (i.e., asymmetry and kurtosis) of the continuous variables employed in the parametric analysis. Since the variables "Offer" and "Request" did not distribute normally, they were log-transformed. To exclude history effects on players' fairness, time series analysis was performed before inferential analyses. No noteworthy effects emerged, and thus we proceeded with the following modeling procedure. Due to the structure of the repeated measures of the data, we adopted the Generalized Linear Mixed Model approach (GLMM) [65] to investigate which socio-demographic and psychological variables influence the bargaining behavior and represent the antecedents of fairness in this context.

\section{Results}

The study results are presented in four different subsections. The first one regards the descriptive statistics of the socio-demographic and psychological characteristics. It also includes the descriptive statistics of the operative variables considered (i.e., Offer, Request, and Fairness). The second subsection reports the effects of the socio-demographic and psychological characteristics on the operative variable "Offer", considering both experimental conditions (i.e., with or without the reputational system). The third subsection deals with the effects of socio-demographic and psychological variables on the operative variable "Request" in both conditions. Finally, the last subsection focuses on the influence of socio-demographic variables and psychological characteristics on "Fairness" when reputation is or is not involved in the game.

\subsection{Descriptive Statistics}

This subsection presents the descriptive statistics of the socio-demographic and psychological characteristics of the participants, as well as the three operative variables of the study: Offer, Request, and Fairness in both experimental conditions. As for the Age, there are no pronounced differences between the two experimental conditions. When reputation is missing the average Age is 18.02 (s.d. = 4.50), while when it is present, it is 17.42 (s.d. = 2.76). The operative variables slightly differ between the two experimental conditions. For the informational purpose, Table 3 reports the original values of the Offer and Request, although they were log-transformed for the inferential analysis. The average Offer when reputation is not involved is 4.45 resources (s.d. $=4.70)$, while when reputation is not provided, it is 4.79 (s.d. = 5.32). As to the average Request, it varies from 6.32 (s.d. = 7.33) in the first condition to 5.86 (s.d. $=7.21$ ) in the second. On average, proposers offer less and request more when reputation is missing, while they allocate more and ask for less when reputation is present. Finally, for what concerns the operative variable "Fairness", it was calculated by subtracting the Requests from the Offers in both conditions. In the first one, the average value of Fairness is -1.82 (s.d. = 8.13), while in the second is -1.07 (s.d. $=8.22$ ), with more fair behaviors registered when the reputational system is provided. The psychological characteristics seem not to differ notably between conditions. As concerns the personality traits, when reputation is missing, lower average values are registered for Neuroticism $(\mathrm{M}=7.41$, s.d. $=4.31)$ and Closeness $(\mathrm{M}=5.35$, s.d. $=3.43)$, while higher average values can be detected for Extraversion $(M=11.01$, s.d. $=3.08)$, Agreeableness $(M=11.27$, s.d. $=3.73)$, 
and Consciousness $(M=8.41$, s.d. =3.78). On the contrary, when reputation is present, higher average values are registered for Neuroticism $(M=7.46$, s.d. $=3.78)$ and Closeness $(M=5.45$, s.d. $=4)$, while lower average values can be observed for Extraversion $(\mathrm{M}=10.94$, s.d. = 3.63), Agreeableness $(M=11.12$, s.d. $=3.75)$, and Consciousness $(M=8.02$, s.d. $=4.14)$. Finally, when the reputational system is involved, higher average values can be observed for Self-Efficacy $(\mathrm{M}=18.26$, s.d. $=3.83)$ and Sense of Community $(M=23.71$, s.d. $=4.58)$. When reputation is missing, the values of Self-Efficacy $(\mathrm{M}=10.08$, s.d. $=4.37)$ and classroom Sense of Community $(\mathrm{M}=23.40$, s.d. $=5.36)$ are averagely lower.

Table 3. Descriptive statistics. In the table are reported the participants' socio-demographic and psychological characteristics, as well as their game behavior playing as proposers.

\begin{tabular}{lcccc}
\hline \multicolumn{4}{c}{ Descriptive Statistics of the Study's Variables } \\
\hline & Rep OFF & \multicolumn{2}{c}{ Rep ON } \\
\hline Variable & M & s.d. & M & s.d. \\
\hline Age & 18.02 & 4.50 & 17.42 & 2.76 \\
Offer & 4.45 & 4.70 & 4.79 & 5.32 \\
Request & 6.32 & 7.33 & 5.86 & 7.21 \\
Fairness & -1.82 & 8.13 & -1.07 & 8.22 \\
Neuroticism & 7.41 & 4.31 & 7.46 & 3.78 \\
Extraversion & 11.01 & 3.08 & 10.94 & 3.63 \\
Agreeableness & 11.27 & 3.73 & 11.12 & 3.75 \\
Closeness & 5.35 & 3.43 & 5.45 & 4 \\
Conscientiousness & 8.41 & 3.78 & 8.02 & 4.14 \\
Self-Efficacy & 18.26 & 3.83 & 18.08 & 4.37 \\
Sense of Community & 23.71 & 4.58 & 23.40 & 5.36 \\
\hline deviation; Rep OFF = Reputation system missing; Rep ON = Reputation system present.
\end{tabular}

\subsection{Effects of Socio-Demographic and Psychological Characteristics on the Offer}

In this subsection, we identify which variables influence the Offer made by the player in an online bargaining game, when a reputational system is or is not provided. Through the GLMM procedure, we verify if the player's offer would differ depending on his socio-demographic and psychological characteristics, as well as in relation to the existence (or not) of a reputational system.

As reported in Table 4, when reputation is involved in an online bargaining game, individuals with high Extraversion seem, on average, to offer more to their counterparts compared to people with low levels of this personality trait. Offers coming from elders and males are also more generous. When reputation is not involved in the game, people with high levels of Extraversion appear to behave oppositely, allocating fewer resources than those with low Extraversion. Also, individuals who emerge as particularly agreeable seem to diminish their offers. On the contrary, Conscientiousness and Neuroticism traits, as well as high levels of Sense of Community and Self-Efficacy, appear to promote higher offers.

\subsection{Effects of Socio-Demographic and Psychological Characteristics on the Request}

This subsection is dedicated to the variables that affect the Request made by the participant of the bargaining game online, both when reputation is or is not considered. The GLMM technique allows testing whether the participant's request would change based on his socio-demographic and psychological characteristics, and depending on the experimental condition (i.e., reputation off or on).

As shown by Table 5, when the reputational system is not involved in the online bargaining game, individuals with high levels of Extraversion, not only tend to offer more to their counterparts, but they also ask for more. At the same time, closed individuals appear to request more resources if compared with open ones, while people with high levels of Agreeableness appear to demand less. When the reputational system is provided, different dynamics of the request behavior emerge in the game. In fact, individuals with high levels of Extraversion and Closeness appear to behave oppositely, asking 
for less respect to the previous scenario and individuals with low levels of these traits. On the contrary, agreeable people show the same behavior, requesting fewer resources also in this condition. Finally, when reputation is involved, other variables emerge as relevant in predicting the request behavior: Neuroticism, Self-Efficacy, and age. In particular, high levels of Neuroticism trait and Self-Efficacy promote higher requests, while age determines low demands.

Table 4. GLMM 1. Socio-demographic and Psychological predictors of offer behavior in each condition.

\begin{tabular}{|c|c|c|c|}
\hline \multicolumn{4}{|c|}{ Predictors of the Offer } \\
\hline Best Model & $\mathbf{F}$ & df-1 (2) & \\
\hline Offer Rep OFF & $10.482^{* * *}$ & $3(1516)$ & \\
\hline Offer Rep ON & $8.333^{* * *}$ & $6(1527)$ & \\
\hline \multicolumn{4}{|c|}{ Fixed coefficients for Rep OFF } \\
\hline Factors & Coefficient $(\beta)$ & Student $\mathbf{t}$ & $p$. \\
\hline Extraversion & 0.027 & 3.50 & 0.001 \\
\hline Age & 0.011 & 2.19 & 0.029 \\
\hline Gender (M) & 0.152 & 3.20 & 0.001 \\
\hline \multicolumn{4}{|c|}{ Fixed coefficients for Rep ON } \\
\hline Factors & Coefficient $(\beta)$ & Student $t$ & $p$. \\
\hline Extraversion & -0.029 & -3.46 & 0.001 \\
\hline Agreeableness & -0.028 & -3.87 & 0.001 \\
\hline Conscientiousness & 0.021 & 3.31 & 0.001 \\
\hline Neuroticism & 0.019 & 2.92 & 0.004 \\
\hline Sense of Community & 0.017 & 3.47 & 0.001 \\
\hline Self-Efficacy & 0.026 & 3.61 & 0.001 \\
\hline
\end{tabular}

Table 5. GLMM 2. Socio-demographic and Psychological predictors of request behavior in each condition.

\begin{tabular}{|c|c|c|c|c|}
\hline \multicolumn{5}{|c|}{ Predictors of the Request } \\
\hline Best Model & Akaike & F & df-1 (2) & \\
\hline Request Rep OFF & 3239.906 & $7528^{* * *}$ & $3(1286)$ & \\
\hline Request Rep ON & 3331.380 & $18,604^{* * *}$ & $6(1309)$ & \\
\hline \multicolumn{5}{|c|}{ Fixed coefficients for Rep OFF } \\
\hline Factors & & Coefficient $(\beta)$ & Student $t$ & $p$. \\
\hline Extraversion & & 0.022 & 2.73 & 0.006 \\
\hline Agreeableness & & -0.017 & -2.76 & 0.006 \\
\hline Closeness & & 0.024 & 3.42 & 0.001 \\
\hline \multicolumn{5}{|c|}{ Fixed coefficients for Rep ON } \\
\hline Factors & & Coefficient $(\beta)$ & Student $t$ & $p$. \\
\hline Extraversion & & -0.032 & -3.98 & 0.001 \\
\hline Agreeableness & & -0.017 & -2.38 & 0.017 \\
\hline Closeness & & -0.020 & -2.87 & 0.004 \\
\hline Neuroticism & & 0.033 & 4.60 & 0.001 \\
\hline Self-Efficacy & & 0.029 & 3.97 & 0.001 \\
\hline Age & & -0.079 & -8.68 & 0.001 \\
\hline
\end{tabular}

\subsection{Effects of Socio-Demographic and Psychological Characteristics on Fairness}

Intending to indicate the antecedents of Fairness, this subsection presents the variables that influence the Proposer's fair behavior in an online bargaining game when reputation is present (or 
missing) during the interactions. We verify which socio-demographic and psychological variables impact fair behaviors and if the presence of a reputational system in this context would affect them using the Generalized Linear Mixed Models. Participants' Fairness is calculated by subtracting Requests from Offers. In other words, it represents the difference between the number of resources the Proposers ask and allocate. Table 6 shows that when the reputational system is missing, people with high Sense of Community seem to be fairer during bargaining interactions. In contrast, individuals who distinguish themselves for their high levels of Self-Efficacy tend to offer less than they request (i.e., behaving unfairly). Age also plays a role in determining participants' Fairness. In particular, older players tend to play more fairly than younger ones. When reputation characterizes the game context, Sense of Community and Age preserve their positive effects on fair behaviors, although the beta coefficient of the Sense of Community may suggest a milder effect of this construct on Fairness. At the same time, closed individuals appear to be fair bargainers, probably thanks to their tendency to ask for fewer resources when reputation is involved, while Neuroticism seems to hinder fair behaviors. No effects of Self-Efficacy emerge for this condition.

Table 6. GLMM 3. Socio-demographic and Psychological predictors of fair behavior in each condition.

\begin{tabular}{|c|c|c|c|c|}
\hline \multicolumn{5}{|c|}{ Predictors of Fairness } \\
\hline Best Model & Akaike & $\mathbf{F}$ & df-1 (2) & \\
\hline Fairness Rep OFF & 10953.659 & $11.968^{* * *}$ & $3(1557)$ & \\
\hline Fairness Rep ON & 11252.259 & $11.501^{* * *}$ & $4(1595)$ & \\
\hline \multicolumn{5}{|c|}{ Fixed coefficients for Rep OFF } \\
\hline Factors & & Coefficient $(\beta)$ & Student $\mathbf{t}$ & $p$. \\
\hline Sense of Community & & 0.196 & 4.33 & 0.001 \\
\hline Self-Efficacy & & -0.143 & -2.62 & 0.009 \\
\hline Age & & 0.169 & 3.74 & 0.001 \\
\hline \multicolumn{5}{|c|}{ Fixed coefficients for Rep ON } \\
\hline Factors & & Coefficient $(\beta)$ & Student $t$ & $p$ \\
\hline Sense of Community & & 0.084 & 1.99 & 0.047 \\
\hline Neuroticism & & -0.135 & -2.16 & 0.031 \\
\hline Closeness & & 0.130 & 2.27 & 0.023 \\
\hline Age & & 0.374 & 4.59 & 0.001 \\
\hline
\end{tabular}

To statistically test the differences among treatments, thus having a more comprehensive understanding of our results, we carried out a new GLMM procedure that included both conditions (i.e., Rep ON and Rep OFF) at the same time.

As we can gather from Table 7, reputation, age, sense of community, and self-efficacy directly affected people's fairness, which means that their effect is mostly independent of the reputation system. Except for self-efficacy that appeared to diminish fairness, the other parameters increased it. Instead, both Closeness and Neuroticism effects seem to be condition-dependent (i.e., we have interaction effects). In other words, we appreciated significant differences between the two conditions for both these psychological antecedents. When reputation was active in the game, Closeness increased fairness and Neuroticism decreased it, while their effects were not noticeable in the Reputation OFF condition. 
Table 7. GLMM 4. Final Socio-demographic and Psychological predictors fairness across conditions.

\begin{tabular}{|c|c|c|c|c|}
\hline \multicolumn{5}{|c|}{ Predictors of Fairness } \\
\hline Best Model & Akaike & F & df-1 (2) & \\
\hline Fairness Final Model & 22176.750 & $11.163^{* * *}$ & $8(3152)$ & \\
\hline \multicolumn{5}{|c|}{ Fixed coefficients } \\
\hline Factors & & Coefficient $(\beta)$ & Student $t$ & $p$. \\
\hline Reputation Condition & (Rep. ON) & 1.42 & 2.79 & 0.005 \\
\hline Sense of Community & & 1.93 & 6.35 & 0.001 \\
\hline Self-Efficacy & & -1.08 & -3.55 & 0.001 \\
\hline Age & & 1.39 & 3.51 & 0.001 \\
\hline Closeness X Rep ON & & 1.30 & 3.14 & 0.002 \\
\hline Neuroticism X Rep O & & -0.64 & -1.54 & 0.048 \\
\hline
\end{tabular}

\section{Discussion}

The present study aims at extending previous findings on the impact of reputational systems on people's pro-social behaviors (i.e., Fairness) within a social dilemma framework [21]. Driven by literature evidence, this work focuses on identifying which socio-demographic and psychological characteristics represent the antecedents of Fairness in an online bargaining game context, paying attention to the influence of reputation on pro-social behaviors. The game employed to investigate the socio-psychological antecedents of Fairness was played online, a peculiar environment that can promote local adhesion to the norm because of its features and the psychological processes it triggers [66]. Since reputation has been conceptualized as a way to manifest local norms [27], increased adhesion to reputation can be expected in this context. Consequently, including a reputational system in the online bargaining game should increase its capability of exerting social influence and favoring the onset of Fairness.

Two experimental conditions were compared: reputation off and reputation on. In the first case, the participants played without the reputational system, while in the second one it was included. The difference between the two conditions lay in the players' mere awareness of the system's presence; in fact, it did not have any effect on them or on the game purposes, since they were playing as Proposers (while the system concerned the Observers). In this respect, it is essential to highlight that when reputation was involved in the game, it was not directly attributed to the players who were filling such roles; therefore, they should not have been under its influence while bargaining. Literature contributions show that when allocating resources, players tend to change their game conduct [67], behaving more or less fairly, consistently with the presence (or the absence) of the reputational system [21].

The Proposers' Offers and Requests were exploratively analyzed along with their socio-demographic and psychological characteristics to identify the antecedents of Fairness (i.e., calculated subtracting the latter from the former).

The descriptive statistics provide initial information about the participants' behavior in each experimental condition. On average, when the reputational system was not involved in the game, the players allocated less and requested more resources to their counterparts, behaving less fairly. At the same time, when playing within the reputational framework, they acted oppositely, being more generous, less demanding, and fairer. The descriptive statistics and the final model presented appear to be in line with previous research, which found high Fairness when the interactions occurred in a context characterized by reputation [21].

From the inferential analysis, it is possible to assume which are the socio-psychological antecedents of Fairness, deepening the knowledge of the factors that affect Offer, Request, and Fairness itself depending on the experimental conditions. 


\subsection{Offer and Request Behaviors}

In general, as summarized by Table 8 , when reputation is not included in the game, less socio-psychological characteristics appear to influence bargaining behavior, while the number of psychological variables that come into play increases when it is included.

Table 8. Psychological antecedents of fairness. In the table is reported a summary of the socio-psychological characteristics that influence fair bargaining behaviors with and without a reputational system.

\begin{tabular}{|c|c|c|}
\hline \multicolumn{3}{|c|}{ Summary of Fairness Antecedents } \\
\hline Variable & Reputation OFF & Reputation ON \\
\hline Offer & $\begin{array}{l}\text { Extraversion }(+) \\
\text { Age }(+) \\
\text { Gender }(\mathrm{M})(+)\end{array}$ & $\begin{array}{c}\text { Extraversion }(-) \\
\text { Agreeableness }(-) \\
\text { Conscientiousness }(+) \\
\text { Neuroticism }(+) \\
\text { Sense of Community }(+) \\
\text { Self-Efficacy }(+)\end{array}$ \\
\hline Request & $\begin{array}{l}\text { Extraversion (+) } \\
\text { Agreeableness (-) } \\
\text { Closeness }(+)\end{array}$ & $\begin{array}{c}\text { Extraversion }(-) \\
\text { Agreeableness }(-) \\
\text { Closeness }(-) \\
\text { Neuroticism }(+) \\
\text { Self-Efficacy }(+) \\
\text { Age }(-)\end{array}$ \\
\hline Fairness & $\begin{array}{c}\text { Sense of Community }(+) \\
\text { Self-Efficacy }(-) \\
\text { Age }(+)\end{array}$ & $\begin{array}{c}\text { Sense of Community }(+) \\
\text { Self-Efficacy }(-) \\
\text { Neuroticism }(-) \\
\text { Closeness }(+) \\
\text { Age }(+)\end{array}$ \\
\hline
\end{tabular}

Note: $+=$ Positive relationship expected; $-=$ Negative relationship expected

In particular, when reputation is off, more generous Offers come from males, elders, and individuals with high levels of Extraversion, who also make higher Requests. On the contrary, when the reputational system is included in the game, people with the Extraversion trait reverse their behavior, offering and asking for fewer resources. Agreeableness trait appears to be associated with lower Offers and Requests when reputation is in the game, and with small Requests when reputation is not involved. Individuals characterized by high levels of Conscientiousness and Sense of Community, appear to allocate more resources when the reputational system is inserted in the game context. Moreover, when the bargainings occur with reputation, Neuroticism and Self-Efficacy arise as positively associated both with large Offers and Requests. Finally, closed players seem to ask for more resources when reputation is not in the context, while they appear to request less when the system is on, just as elder participants do.

\subsection{Checking Hypotheses on Fairness}

As regards Fairness, consistent results between conditions characterize Age and Sense of Community. Confirming the study second hypothesis (H2), maturity appears to be positively associated with pro-sociality: as the participant's age grows, Fairness increases. This result seems to be coherent with previous literature findings that identified a positive relationship between Age and pro-social behaviors [21]. Moreover, players' Sense of Community emerges as being associated with fair bargaining behaviors both when the reputational system is included and when it is not, accordingly with the fourth hypothesis (H4). Along the same line of De Cremer's work, [52], individuals with high scores of Sense of Community appear to be more cooperative, pro-social, and fair during exchanges, promoting Fairness regardless of the context features. Self-Efficacy results as negatively associated with Fairness as well, thus partially disconfirming the third hypothesis of the study (H3). Finally, 
focusing on the personality traits and addressing the first hypothesis of the research (H1), it should be noted that players who reported high levels of Neuroticism behaved unfairly during the interactions, as well as Closed individual pursued fair bargainings when the reputational system was included in the game. No significant effects emerged on the other personality traits included in the first hypothesis (i.e., extraversion, agreeableness, and conscientiousness). According to the literature, neurotic individuals perform less fair behaviors when reputation exerts its social influence probably because they are less sensitive to the social context norms, tend to adhere less to such standards, and to be less affected by their requirements [34]. At the same time, closed people appear to be particularly susceptible to the social influence produced by norms, such as reputation; therefore, in accordance with the literature, this personality trait promotes the emergence of Fairness among interacting individuals [34].

\subsection{Study Limitations and Future Perspectives}

Overall, the present work has some limitations. The study sample was mostly made of adolescents and young adults from Tuscany; therefore, it is not representative of the whole Italian population. Future research could consider different age groups from the entire nation as well as sort out participants by social class and occupation. Age emerged as a factor capable of positively influencing fair behaviors; therefore, it could be interesting to investigate whether there would be shifting in its effects over time. Another limitation can be represented by the novelty of the experimental game employed. In fact, despite representing a fresh way to deepen the knowledge of bargaining dynamics online with the involvement of reputation and its effects on fairness, there are no normative data available to compare the results to. It may be possible that due to the peculiarities often game, some literature hypothesis did not find a complete confirmation.

\subsection{Application Areas}

Most reputational systems available today are built to directly influence the behavior of a specific individual and work to overcome phenomena such as free-riding [68] and social loafing [69]. For all those online platforms that rely on a reputational system to manage the interactions among their users, it could be useful to consider the impact that such a system has on those who are not affected by it personally. In fact, including reputation in the exchanges promotes fairness among individuals who do not represent the system target, favoring fair interactions [21]. Recent research in the same field provided evidence on how third parties' fairness perception could be influenced by the relationship between the reviewer's reputation and the responses of the webcare in a rating system [70]. The consideration of the socio-demographics and psychological antecedents of such interactions can drive companies to build platforms tailored to their users' features, promoting fairness through reputation among target and non-target individuals. Furthermore, looking at the individual differences in terms of reputation susceptibility when interacting online, can help businesses and institutions to improve the robustness and the effectiveness of their platforms. Moreover, knowing which psychological characteristics hinder reputation purposes (e.g., promoting fairness and pro-social behaviors) can be another element that might their performance. Also, our work sheds light on those features that can boost pro-social behaviors independently of reputation mechanisms. Building an online/virtual sense of community could be a valuable strategy to foster citizens' online social coordination [71], sustainability [72-74], as well as wellbeing through a wise of technology [75,76].

Author Contributions: Conceptualization, M.D. and A.G.; Data curation, M.D., S.C., M.F. and A.G.; Investigation, M.D.; Methodology, M.D. and A.G.; Formal analysis, M.D., S.C., M.F. and A.G.; Writing-original draft, M.D., S.C., M.F. and A.G. All authors have read and agreed to the published version of the manuscript.

Funding: This research received no external funding.

Conflicts of Interest: The authors declare no conflict of interest. 


\section{References}

1. McCrae, R.R.; Costa, P.T., Jr. Personality trait structure as a human universal. Am. Psychol. 1997, 52, 509. [CrossRef] [PubMed]

2. Barry, B.; Stewart, G.L. Composition, process, and performance in self-managed groups: The role of personality. J. Appl. Psychol. 1997, 82, 62. [CrossRef] [PubMed]

3. Sagiv, L.; Sverdlik, N.; Schwarz, N. To compete or to cooperate? Values' impact on perception and action in social dilemma games. Eur. J. Soc. Psychol. 2011, 41, 64-77. [CrossRef]

4. Luse, A.; McElroy, J.C.; Townsend, A.M.; Demarie, S. Personality and cognitive style as predictors of preference for working in virtual teams. Comput. Hum. Behav. 2013, 29, 1825-1832. [CrossRef]

5. Collodi, S.; Panerati, S.; Imbimbo, E.; Stefanelli, F.; Duradoni, M.; Guazzini, A. Personality and Reputation: A Complex Relationship in Virtual Environments. Future Internet 2018, 10, 120. [CrossRef]

6. Resnick, P.; Kuwabara, K.; Zeckhauser, R.; Friedman, E. Reputation systems. Commun. ACM 2000, 43, 45-48. [CrossRef]

7. Henrich, J.; Boyd, R.; Bowles, S.; Camerer, C.; Fehr, E.; Gintis, H.; McElreath, R. In search of homo economicus: Behavioral experiments in 15 small-scale societies. Am. Econ. Rev. 2001, 91, 73-78. [CrossRef]

8. Kahneman, D.; Tversky, A. Prospect Theory of Decisions Under Risk. Econometrica 1979, 47, $1156-1167$. [CrossRef]

9. Merrick, K.; Hardhienata, M.; Shafi, K.; Hu, J. A survey of game theoretic approaches to modelling decision-making in information warfare scenarios. Future Internet 2016, 8, 34. [CrossRef]

10. Kimbrough, E.O.; Vostroknutov, A. Norms make preferences social. J. Eur. Econ. Assoc. 2016, 14, 608-638. [CrossRef]

11. Roberts, G. Competitive altruism: from reciprocity to the handicap principle. Proc. R. Soc. Lond. Ser. Biol. Sci. 1998, 265, 427-431. [CrossRef]

12. Fehr, E.; Fischbacher, U. The nature of human altruism. Nature 2003, 425, 785-791. [CrossRef]

13. Sanfey, A.G. Social decision-making: insights from game theory and neuroscience. Science 2007, 318, 598-602. [CrossRef] [PubMed]

14. Caliendo, M.; Fossen, F.; Kritikos, A. Trust, positive reciprocity, and negative reciprocity: Do these traits impact entrepreneurial dynamics? J. Econ. Psychol. 2012, 33, 394-409. [CrossRef]

15. Gunnthorsdottir, A.; McCabe, K.; Smith, V. Using the Machiavellianism instrument to predict trustworthiness in a bargaining game. J. Econ. Psychol. 2002, 23, 49-66. [CrossRef]

16. Semmann, D.; Krambeck, H.J.; Milinski, M. Reputation is valuable within and outside one's own social group. Behav. Ecol. Sociobiol. 2005, 57, 611-616. [CrossRef]

17. Milinski, M.; Semmann, D.; Krambeck, H.J.; Marotzke, J. Stabilizing the Earth's climate is not a losing game: Supporting evidence from public goods experiments. Proc. Natl. Acad. Sci. USA 2006, 103, 3994-3998. [CrossRef]

18. Rockenbach, B.; Milinski, M. The efficient interaction of indirect reciprocity and costly punishment. Nature 2006, 444, 718-723. [CrossRef]

19. Semmann, D.; Krambeck, H.J.; Milinski, M. Strategic investment in reputation. Behav. Ecol. Sociobiol. 2004, 56, 248-252. [CrossRef]

20. Sauermann, J. Reputation Formation in Bargaining. Partners vs. Strangers in the Ultimatum Game. In Jahrbuch für Handlungs-und Entscheidungstheorie; Springer: Berlin/Heidelberg, Germany, 2019; pp. 179-189.

21. Duradoni, M.; Paolucci, M.; Bagnoli, F.; Guazzini, A. Fairness and Trust in Virtual Environments: The Effects of Reputation. Future Internet 2018, 10, 50. [CrossRef]

22. Nowak, M.A.; Page, K.M.; Sigmund, K. Fairness versus reason in the ultimatum game. Science 2000, 289, $1773-1775$. [CrossRef] [PubMed]

23. Bicchieri, C.; Chavez, A. Behaving as expected: Public information and fairness norms. J. Behav. Decis. Mak. 2010, 23, 161-178. [CrossRef]

24. Webster, M.M.; Ward, A.J. Personality and social context. Biol. Rev. 2011, 86, 759-773. [CrossRef] [PubMed]

25. Postmes, T.; Spears, R.; Sakhel, K.; De Groot, D. Social influence in computer-mediated communication: The effects of anonymity on group behavior. Personal. Soc. Psychol. Bull. 2001, 27, 1243-1254. [CrossRef]

26. Spears, R.; Postmes, T.; Lea, M.; Wolbert, A. When are net effects gross products? Communication. J. Soc. Issues 2002, 58, 91-107. [CrossRef] 
27. Baumeister, R.F.; Zhang, L.; Vohs, K.D. Gossip as cultural learning. Rev. Gen. Psychol. 2004, 8, 111. [CrossRef]

28. Okada, I. A Review of Theoretical Studies on Indirect Reciprocity. Games 2020, 11, 27. [CrossRef]

29. Hilbig, B.E.; Zettler, I.; Heydasch, T. Personality, punishment and public goods: Strategic shifts towards cooperation as a matter of dispositional honesty-humility. Eur. J. Personal. 2012, 26, 245-254. [CrossRef]

30. Eckel, C.C.; Grossman, P.J. Altruism in anonymous dictator games. Games Econ. Behav. 1996, 16, $181-191$. [CrossRef]

31. Goldberg, L.R. The structure of phenotypic personality traits. Am. Psychol. 1993, 48, 26. [CrossRef]

32. Koole, S.L.; Jager, W.; van den Berg, A.E.; Vlek, C.A.; Hofstee, W.K. On the social nature of personality: Effects of extraversion, agreeableness, and feedback about collective resource use on cooperation in a resource dilemma. PErsonality Soc. Psychol. Bull. 2001, 27, 289-301. [CrossRef]

33. Volk, S.; Thöni, C.; Ruigrok, W. Personality, personal values and cooperation preferences in public goods games: A longitudinal study. Personal. Individ. Differ. 2011, 50, 810-815. [CrossRef]

34. DeYoung, C.G.; Peterson, J.B.; Higgins, D.M. Higher-order factors of the Big Five predict conformity: Are there neuroses of health? Personal. Individ. Differ. 2002, 33, 533-552. [CrossRef]

35. Proto, E.; Rustichini, A. A reassessment of the relationship between GDP and life satisfaction. PLoS ONE 2013, 8, e79358. [CrossRef] [PubMed]

36. Graziano, W.G.; Tobin, R.M. Agreeableness: Dimension of personality or social desirability artifact? J. Personal. 2002, 70, 695-728.

37. Jensen-Campbell, L.A.; Rosselli, M.; Workman, K.A.; Santisi, M.; Rios, J.D.; Bojan, D. Agreeableness, conscientiousness, and effortful control processes. J. Res. Personal. 2002, 36, 476-489. [CrossRef]

38. Paulhus, D.L.; John, O.P. Egoistic and moralistic biases in self-perception: The interplay of self-deceptive styles with basic traits and motives. J. Personal. 1998, 66, 1025-1060. [CrossRef]

39. Eagly, A.H.; Crowley, M. Gender and helping behavior: A meta-analytic review of the social psychological literature. Psychol. Bull. 1986, 100, 283. [CrossRef]

40. Simpson, B. Sex, fear, and greed: A social dilemma analysis of gender and cooperation. Soc. Forces 2003, 82, 35-52. [CrossRef]

41. Bonacich, P. Norms and cohesion as adaptive responses to potential conflict: An experimental study. Sociometry 1972, 35, 357-375. [CrossRef]

42. Dawes, R.M.; McTavish, J.; Shaklee, H. Behavior, communication, and assumptions about other people's behavior in a commons dilemma situation. J. Personal. Soc. Psychol. 1977, 35, 1. [CrossRef]

43. Brown-Kruse, J.; Hummels, D. Gender effects in laboratory public goods contribution: Do individuals put their money where their mouth is? J. Econ. Behav. Organ. 1993, 22, 255-267. [CrossRef]

44. Sell, J.; Wilson, R.K. Levels of information and contributions to public goods. Soc. Forces 1991, 70, 107-124. [CrossRef]

45. Vugt, M.v.; Cremer, D.D.; Janssen, D.P. Gender differences in cooperation and competition: The male-warrior hypothesis. Psychol. Sci. 2007, 18, 19-23. [CrossRef] [PubMed]

46. Caldwell, M.D. Communication and sex effects in a five-person Prisoner's Dilemma Game. J. Personal. Soc. Psychol. 1976, 33, 273. [CrossRef]

47. Goehring, D.J.; Kahan, J.P. The uniform n-person prisoner's dilemma game: construction and test of an index of cooperation. J. Confl. Resolut. 1976, 20, 111-128. [CrossRef]

48. Sell, J. Gender, strategies, and contributions to public goods. Soc. Psychol. Q. 1997, 60, 252-265. [CrossRef]

49. Lerner, B.S.; Locke, E.A. The effects of goal setting, self-efficacy, competition, and personal traits on the performance of an endurance task. J. Sport Exerc. Psychol. 1995, 17, 138-152. [CrossRef]

50. Piazza, J.; Bering, J.M. Concerns about reputation via gossip promote generous allocations in an economic game. Evol. Hum. Behav. 2008, 29, 172-178. [CrossRef]

51. Sommerfeld, R.D.; Krambeck, H.J.; Milinski, M. Multiple gossip statements and their effect on reputation and trustworthiness. Proc. R. Soc. Biol. Sci. 2008, 275, 2529-2536. [CrossRef]

52. De Cremer, D. Respect and cooperation in social dilemmas: The importance of feeling included. Personal. Soc. Psychol. Bull. 2002, 28, 1335-1341. [CrossRef]

53. Wit, A.P.; Wilke, H.A. The effect of social categorization on cooperation in three types of social dilemmas. J. Econ. Psychol. 1992, 13, 135-151. [CrossRef]

54. Feinberg, M.; Willer, R.; Stellar, J.; Keltner, D. The virtues of gossip: Reputational information sharing as prosocial behavior. J. Personal. Soc. Psychol. 2012, 102, 1015. [CrossRef] [PubMed] 
55. Lampe, C.; Zube, P.; Lee, J.; Park, C.H.; Johnston, E. Crowdsourcing civility: A natural experiment examining the effects of distributed moderation in online forums. Gov. Inf. Q. 2014, 31, 317-326. [CrossRef]

56. Seo, K.K. Utilizing peer moderating in online discussions: Addressing the controversy between teacher moderation and nonmoderation. Am. J. Distance Educ. 2007, 21, 21-36. [CrossRef]

57. Chen, Y.; Xie, J. Third-party product review and firm marketing strategy. Mark. Sci. 2005, 24, $218-240$. [CrossRef]

58. Ma, Y.; Li, F. Detecting review spam: Challenges and opportunities. In Proceedings of the 8th International Conference on Collaborative Computing: Networking, Applications and Worksharing (CollaborateCom), Pittsburgh, PA, USA, 14-17 October 2012; pp. 651-654.

59. Giannini, M.; Pannocchia, L.; Grotto, L.; Gori, A. A measure for counseling: the five factor adjective short test (5-fast). Couns. Ital. Ric. Appl. 2012, 3, 384.

60. Jerusalem, M.; Schwarzer, R. Self-efficacy as a resource factor in stress appraisal processes. In Self-Efficacy: Thought Control of Action; Taylor \& Francis: Park Avenue/Abingdon, UK, 1992; Volume 195213.

61. Luszczynska, A.; Scholz, U.; Schwarzer, R. The general self-efficacy scale: multicultural validation studies. J. Psychol. 2005, 139, 439-457. [CrossRef]

62. Scholz, U.; Doña, B.G.; Sud, S.; Schwarzer, R. Is general self-efficacy a universal construct? Psychometric findings from 25 countries. Eur. J. Psychol. Assess. 2002, 18, 242. [CrossRef]

63. Rovai, A.P.; Wighting, M.J.; Lucking, R. The classroom and school community inventory: Development, refinement, and validation of a self-report measure for educational research. Internet High. Educ. 2004, 7, 263-280. [CrossRef]

64. Rovai, A.P. Development of an instrument to measure classroom community. Internet High. Educ. 2002, 5, $197-211$. [CrossRef]

65. McCulloch, C.E.; Searle, S.R. Generalized, Linear, and Mixed Models (Wiley Series in Probability and Statistics); Wiley: Hoboken, NJ, USA, 2001.

66. Reicher, S.D.; Spears, R.; Postmes, T. A social identity model of deindividuation phenomena. Eur. Rev. Soc. Psychol. 1995, 6, 161-198. [CrossRef]

67. Duradoni, M.; Gronchi, G.; Bocchi, L.; Guazzini, A. Reputation matters the most: The reputation inertia effect. In Human Behavior and Emerging Technologies; Wiley: Hoboken, NJ, USA, 2020.

68. Stigler, G.J. Free riders and collective action: An appendix to theories of economic regulation. Bell J. Econ. Manag. Sci. 1974, 5, 359-365. [CrossRef]

69. Karau, S.J.; Williams, K.D. Social loafing: A meta-analytic review and theoretical integration. J. Personal. Soc. Psychol. 1993, 65, 681. [CrossRef]

70. Raju, A. Can reviewer reputation and webcare content affect perceived fairness? J. Res. Interact. Mark. 2019, 13. [CrossRef]

71. Condor, S. Towards a social psychology of citizenship? Introduction to the special issue. J. Community Appl. Soc. Psychol. 2011, 21, 193-201. [CrossRef]

72. Berardi, U. Sustainability assessment of urban communities through rating systems. Environ. Dev. Sustain. 2013, 15, 1573-1591. [CrossRef]

73. Spagnolli, A.; Corradi, N.; Gamberini, L.; Hoggan, E.; Jacucci, G.; Katzeff, C.; Broms, L.; Jonsson, L. Eco-feedback on the go: Motivating energy awareness. Computer 2011, 44, 38-45. [CrossRef]

74. Too, L.; Bajracharya, B. Sustainable campus: Engaging the community in sustainability. Int. J. Sustain. High. Educ. 2015, 16, 57-71. [CrossRef]

75. Duradoni, M.; Innocenti, F.; Guazzini, A. Well-Being and Social Media: A Systematic Review of Bergen Addiction Scales. Future Internet 2020, 12, 24. [CrossRef]

76. Guazzini, A.; Duradoni, M.; Capelli, A.; Meringolo, P. An explorative model to assess individuals' phubbing risk. Future Internet 2019, 11, 21. [CrossRef]

(C) 2020 by the authors. Licensee MDPI, Basel, Switzerland. This article is an open access article distributed under the terms and conditions of the Creative Commons Attribution (CC BY) license (http:/ / creativecommons.org/licenses/by/4.0/). 